\title{
Long-living Plasmoids from an Atmospheric Water Discharge
}

\author{
A Versteegh ${ }^{1,2}$, K Behringer ${ }^{3}$, U Fantz ${ }^{3}$, G Fussmann ${ }^{1,3}$, B Jüttner ${ }^{1}$, S Noack ${ }^{1,4}$ \\ ${ }^{1}$ Institut für Physik der Humboldt-Universität zu Berlin, Newtonstr. 15, 12489 Berlin, Germany* \\ 2 Technische Universiteit Eindhoven, Netherlands \\ ${ }^{3}$ Max-Planck-Institut für Plasmaphysik, Germany, EURATOM Association and \\ 4 Universität Leipzig, Germany
}

\begin{abstract}
Ball-like plasmoids were generated from discharging a capacitor bank via a water surface. In the autonomous stage after current zero they have diameters up to $0.2 \mathrm{~m}$ and lifetimes of some hundreds of milliseconds, thus resembling ball lightning in some way. They were studied by applying high speed cameras, electric probes, calorimetric measurements, and spectroscopy. The plasmoids are found to consist of a true plasma surrounded by a cold envelope. Decreasing electron densities in the order of $10^{20} \mathrm{~m}^{-3}$ to $10^{22} \mathrm{~m}^{-3}$ were measured from Stark broadening in the initial (formation) phase. The electron temperature is estimated to be $2000-5000 \mathrm{~K}$ during most of the plasmoid's lifetime. The temperature of the neutral particles can exceed $1300 \mathrm{~K}$. Calcium hydroxide molecular band emission is the major source of visible radiation in the autonomous phase. Chemiluminescence reactions between dissociation products of water and dissolved calcium are proposed as a source for this emission. The plasmoid's colder boundary layer consists of electric double layers that may attribute to the characteristic shape of the balls.
\end{abstract}

PACS numbers: $52.08 . \mathrm{Mg}, 52.80 . \mathrm{Wq}, 92.60 . \mathrm{Pw}$

\section{INTRODUCTION}

Recently, the generation of luminous plasmoids at atmospheric pressure produced from a medium current water discharge were described in a number of papers (see [1-3] and the references therein). The plasmoids are described as a cold hydrated plasma with a temperature of about $330 \mathrm{~K}[2,4]$, not containing positive charges [1]. The present work repeats these experiments, adding a variety of diagnostics to get better insight into the phenomenon and in particular understand the energy storage mechanism that enables the autonomously radiating behavior. After a short explanation of the experimental setup, the results of the various diagnostics will be discussed. Most attention is given to spectroscopy. A short discussion and conclusions follow at the end.

\section{EXPERIMENTAL SETUP}

Figure 1 shows a schematic of the experimental setup. It is similar to that in refs. [1-3] as far as the discharge system is concerned. The cylindrical discharge vessel made of glass or plastics is filled with tap water or distilled water with salt additives. A copper ring at the bottom of the vessel serves as an anode, while the cathode is the central electrode protruding some millimeters above the water surface. A capacitor bank of $1 \mathrm{mF}$ charged to $4.8 \mathrm{kV}$ is switched to the anode causing a discharge with currents between 10 and 100 A. After 100-150 ms the current is shut down to obtain an autonomous object without external energy supply. As

*Electronic address: alex.versteegh@physik.hu-berlin.de diagnostics have been used: high speed video cameras (500 frames per second), various probes, medium resolution $(\lambda / \Delta \lambda \approx 20,000)$ absolutely calibrated échelle spectrometer with large spectral range (300-800 nm), high resolution $(\lambda / \Delta \lambda \approx 100,000)$ spectrometer, thermocouples (Ni-Cr, up to $1200 \mathrm{~K}$, response time $20 \mathrm{~ms}$ ), pyroelectric sensors with high sensitivity $(>97 \%)$ in the spectral range $0.2-20 \mu \mathrm{m}$, and precision scales to measure the mass loss of the system.

\section{RESULTS}

\section{A. Camera Recordings}

Figure 2 shows the plasmoid's appearance at various times after triggering the capacitor discharge. Initially, the 'streamers' form a spider-like pattern closely above the water-air interface. Above the central electrode the slowly expanding plasma ball emerges. Figure 3 (a) shows the plasmoid $30 \mathrm{~ms}$ after current zero $(t \approx 160 \mathrm{~ms})$. The jet like-structure above the balls is due to a camera effect. At this high camera exposure one sees a distinct boundary of the ball, while at lower exposure inner structures can be seen which are much brighter than the background and change their position rapidly inside the boundary (figure $3(\mathrm{~b})$ ).

Velocity and size of the plasmoids can be determined as a function of time from the high speed camera recordings. This is shown in figure 4 (a). The velocity reaches a constant value of $0.8 \pm 0.1 \mathrm{~m} / \mathrm{s}$ after about $50 \mathrm{~ms}$ and does not change at current zero. Knowing the velocity of the plasmoid, height over the central electrode can be converted into time of arrival of the ball at a certain position and vice versa. This was used for all diagnostic tools. The ball radius increases from about $4 \mathrm{~cm}$ at $30 \mathrm{~ms}$ up to 


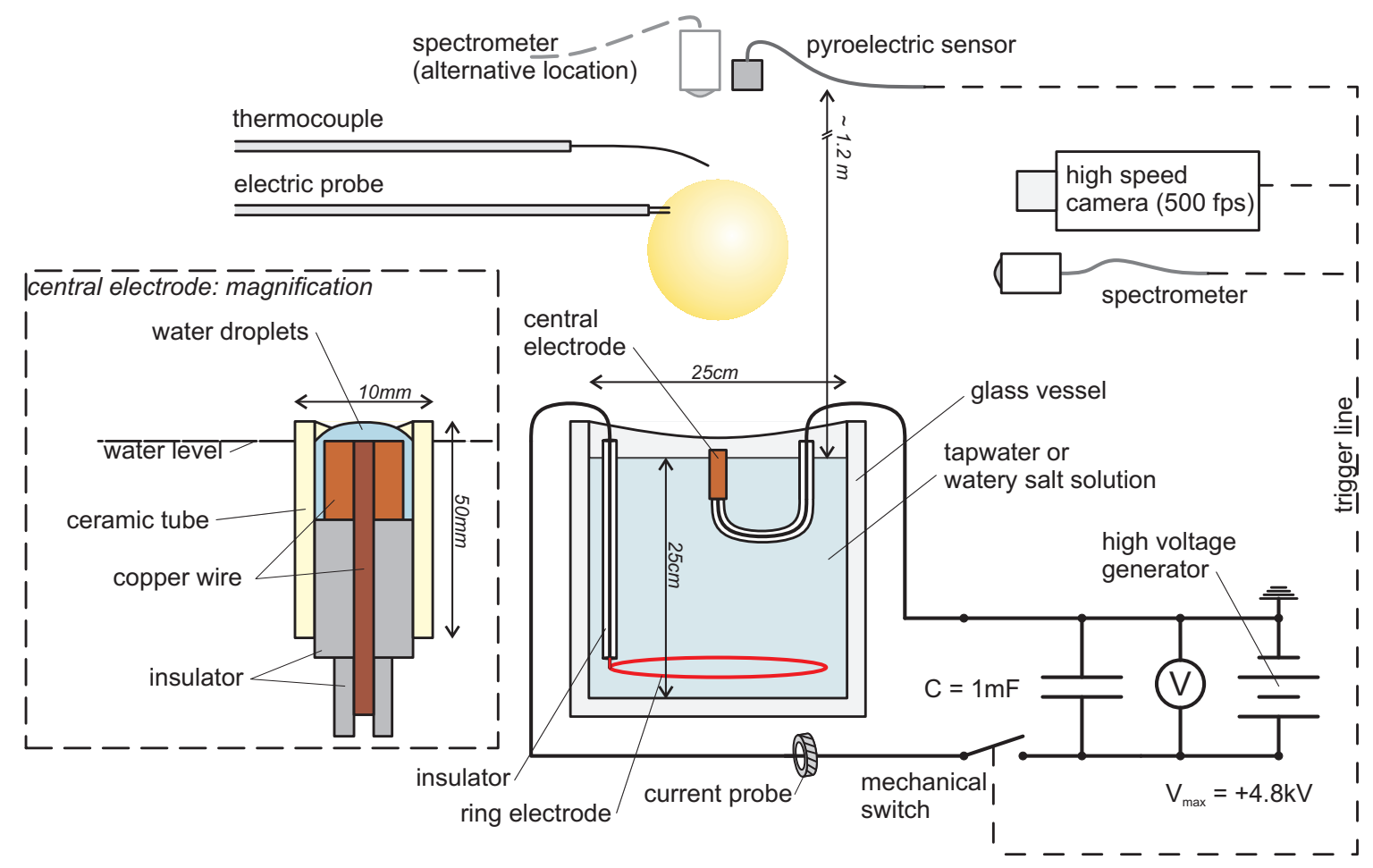

FIG. 1: Schematic of the experiment and overview of diagnostics. A magnification of the central electrode is pictured in the dashed box on the left.

$8 \mathrm{~cm}$ at $250 \mathrm{~ms}$. Inner structures as shown in figure $3(\mathrm{~b})$ have a higher upward velocity up to $3 \mathrm{~m} / \mathrm{s}$ until they reach the upper periphery where they are slowed down and bent to the sides to form a toroidal structure towards the end of the lifetime.

\section{B. Power, Energy and Gas Temperature}

For a typical shot the energy delivered from the capacitor bank to the discharge is about $8 \mathrm{~kJ}$. The current $I_{\text {dis }}$ and ring electrode voltage $V_{\text {ring }}$ of a discharge with tap water are shown in figure 4 (b). The maximum discharge current, as well as the brightness of the plasma balls can be increased by adding salts to the water, increasing the conductivity.

Calorimetric measurements yield that on average about $5 \mathrm{~kJ}$ is spent on heating and evaporation of water; about $0.1 \mathrm{~g}$ water is evaporated per shot. Thus about $3 \mathrm{~kJ}$ is available for the formation of the plasma ball. Figure 4 (c) shows the radiation power in the wavelength range of $0.2-20 \mu \mathrm{m}$, measured with a pyroelectric sensor. In total about $0.7 \mathrm{~kJ}$ are radiated. Hence, a fraction of $0.7 / 3=0.23$ of the available energy is converted into radiation.

The thermocouples measured about $900 \mathrm{~K}$ at $t \approx$ $235 \mathrm{~ms}$ and $600 \mathrm{~K}$ at $t \approx 260 \mathrm{~ms}$. For $t \approx 200 \mathrm{~ms}$ the thermocouples indicated $1300 \mathrm{~K}$ and more, but were damaged during the measurement so that this result is not reliable. The true gas temperature for $t<200 \mathrm{~ms}$ may thus be considerably higher. On the other hand, a sheet of paper can stop the plasma ball without catching fire, thus corroborating the existence of a cool outer layer surrounding the hotter core plasma.

\section{Probe Measurements}

\section{Floating Potential and Space Charge}

Single (and double) Langmuir probes used to measure the floating potential (difference) consisted of wires with $0.1 \mathrm{~mm}$ diameter and a length of about $2 \mathrm{~mm}$. They were connected to a scope via resistors of $50 \mathrm{M} \Omega$, thus in a nearly floating state. In the initial phase $\left(I_{\text {dis }}>0\right)$ single probes show signals reaching up to $200 \mathrm{~V}$. The polarity is positive when applying positive high voltage to the ring electrode and negative for negative high voltage.

As the discharge current reaches zero, the voltage drops sharply to values $<1 \mathrm{~V}$. The polarity is then positive, irrespectively of the polarity of the high voltage. By measuring at several heights the (central) floating potential as a function of time can be deduced. This shows a roughly linear decrease from values around $0.5 \mathrm{~V}$ at $250 \mathrm{~ms}$ to $0.05 \mathrm{~V}$ at $600 \mathrm{~ms}$. These results have been presented elsewhere [5]. 

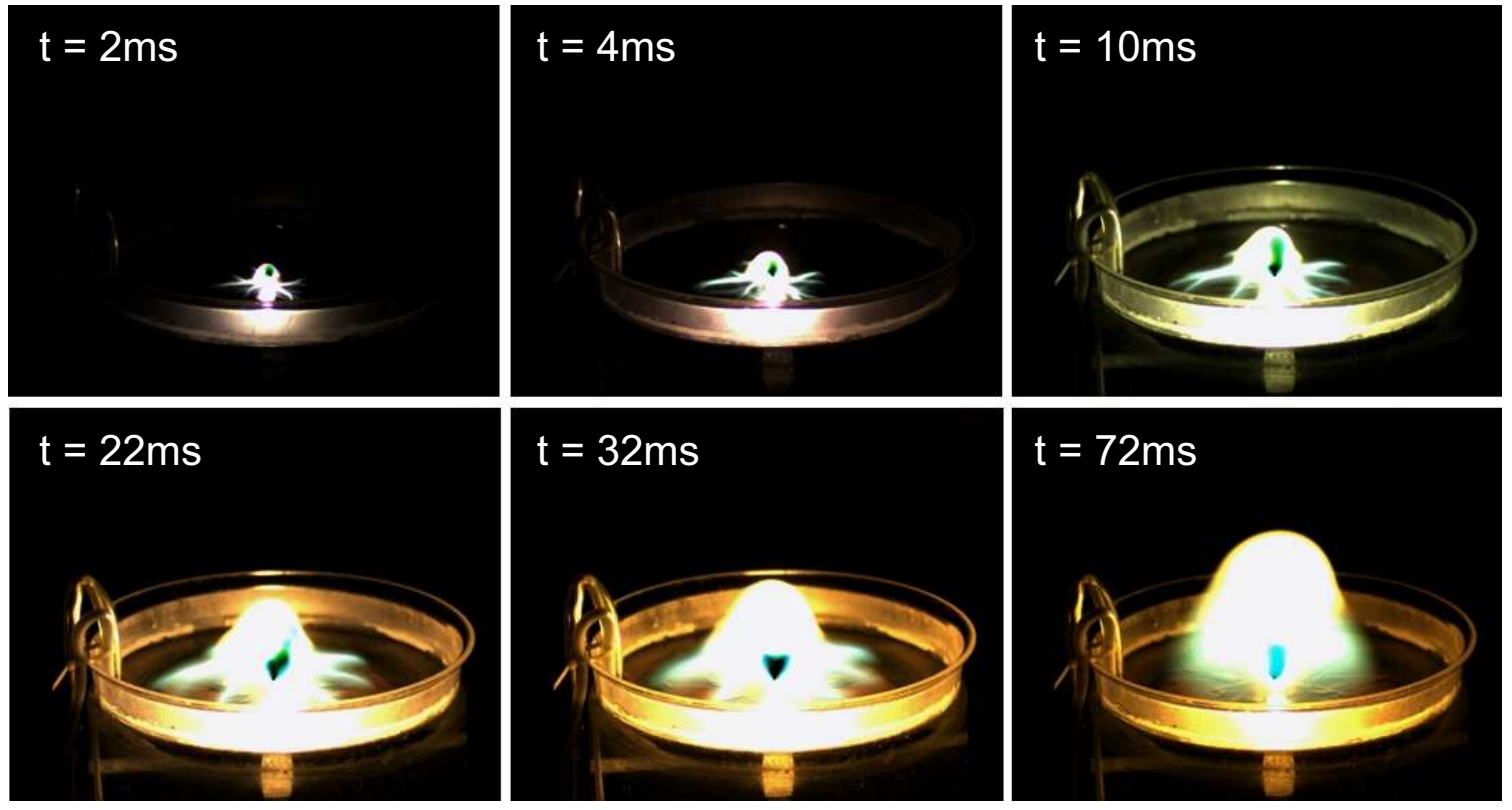

FIG. 2: Series of frames recorded using the high speed camera at different times $t$ after triggering the discharge.

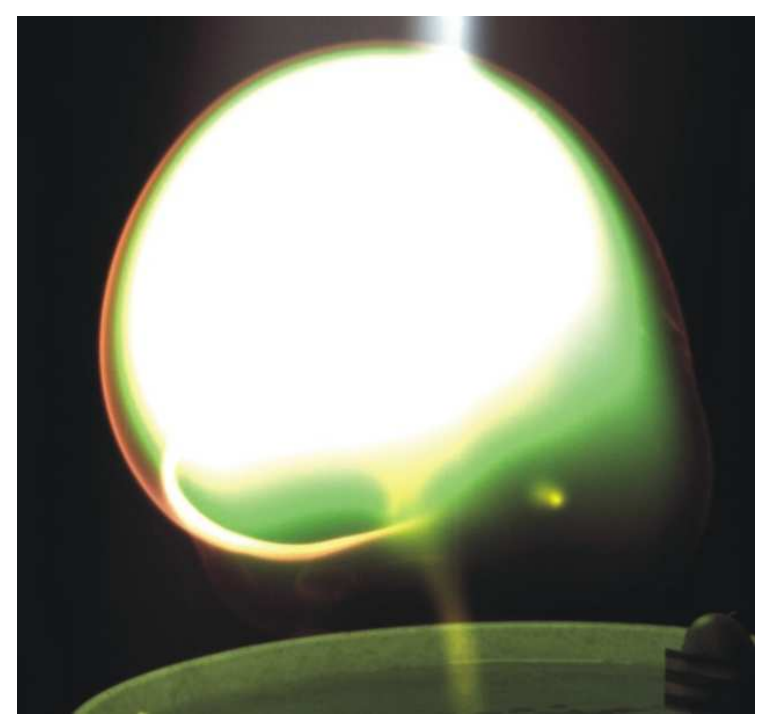

(a) High exposure video capture showing the distinct boundary layer.

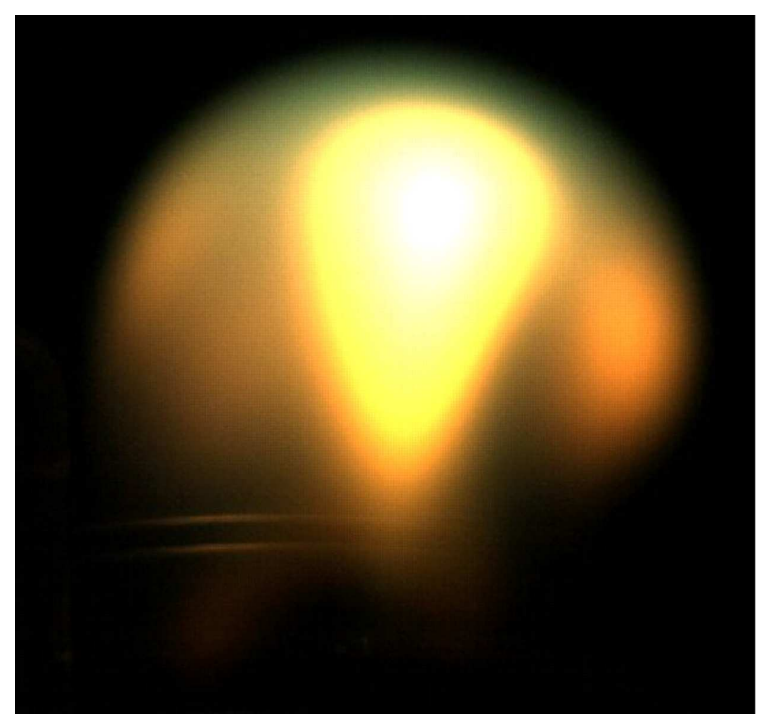

(b) Low exposure video capture showing inner structure of the plasma ball.

FIG. 3: Video captures taken at approximately $30 \mathrm{~ms}$ after current zero $(t \approx 160 \mathrm{~ms})$. The diameter of the ball is $\sim 12 \mathrm{~cm}$; the magnification in both images is approximately equal.

The floating potential difference $\Delta V$ between small double probes at a separation $\Delta x=0.2 \mathrm{~mm}$ (aligned vertically) showed in some cases sharp peaks with duration $<1 \mathrm{~ms}$, as the rising ball passed through the probes. These can be attributed to double layers within the ball or at its boundary. Ignoring gradients in $T_{\mathrm{e}}$ on this small scale, the electric field can be obtained from this difference as $E=\Delta V / \Delta x$. This function can be differentiated and converted to $\mathrm{d} E / \mathrm{d} x$ using the known velocity $v_{\text {ball }}$ of the ball:

$$
\mathrm{d} E / \mathrm{d} x=v_{\text {ball }}^{-1} \mathrm{~d} E / \mathrm{d} t .
$$

The Poisson-equation then yields the space charge density $\rho=\epsilon \mathrm{d} E / \mathrm{d} x$. Figure 5 shows the vertical space charge distribution deduced in this way at three different measurement heights, assuming $\epsilon=\epsilon_{0}$. 

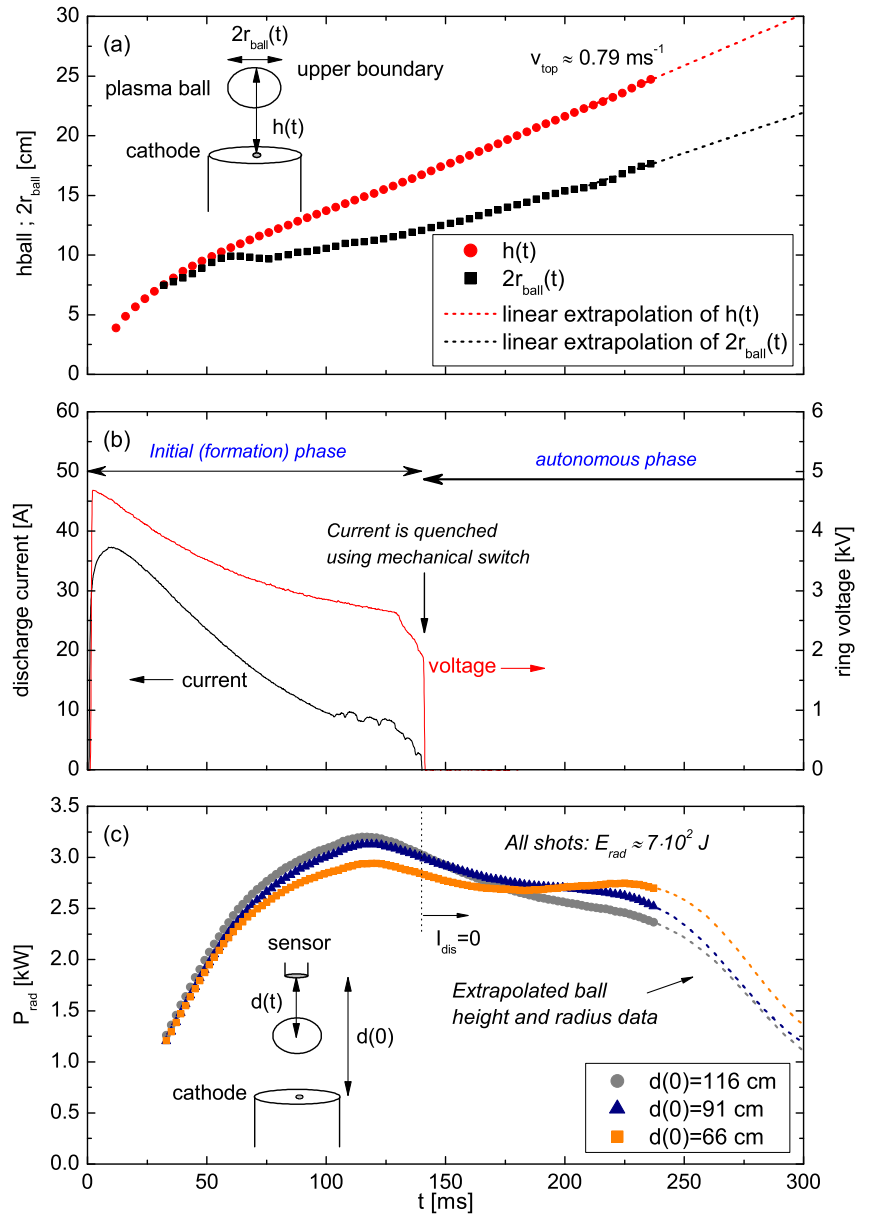

FIG. 4: Time-dependent parameters of the plasmoid: (a) height and diameter measured using the high-speed camera; (b) discharge current and voltage; (c) radiation power measured using a pyroelectric sensor with high sensitivity in the range of $0.2-20 \mu \mathrm{m}$. The lifetime is

divided in an initial (formation) phase and an autonomous phase based on the discharge current value.

\section{Other Probe Measurements}

With non-biased probes (same size as before) towards the end of the initial phase, one measures currents up to $10 \mu \mathrm{A}$ from the positively charged ball. In the autonomous phase at $t \approx 260 \mathrm{~ms}$ these values have decreased to around $20 \mathrm{nA}$. These currents must consist of flows of positively charged ions. Positively or negatively biased probes in the autonomous phase show no current saturation at increasing voltage. Also in the autonomous phase, sweeping double probes at various distances (in the range of 4-20 $\mathrm{mm}$ ) show incomplete saturation at voltages in the range of $-10 \mathrm{~V}$ to $10 \mathrm{~V}$.

The absence of saturation currents is probably caused by collisions in the plasma sheath, due to the high neutral density at atmospheric pressure. Therefore, the currents

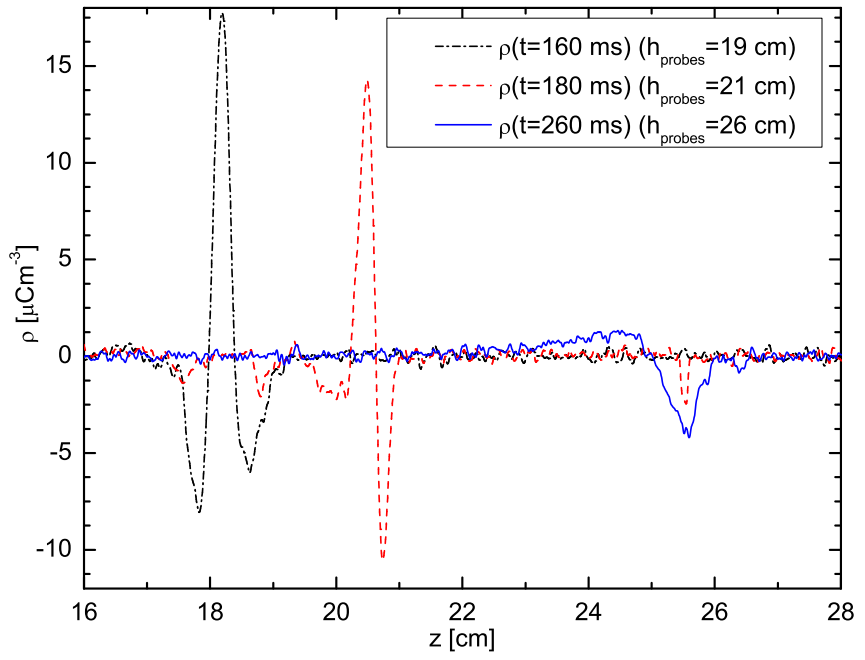

FIG. 5: Space charge density as a function of the height $z$ above the electrode at three different times, assuming

$$
\epsilon=\epsilon_{0} \text {. }
$$

can hardly yield data on the plasma density. Because for floating voltage measurements the currents are small, the resistance of the sheath will have less influence.

\section{Spectroscopy}

\section{Overview Spectra}

In spectra recorded from discharges with tap water, lines of the following atomic species have been identified: $\mathrm{Ca}, \mathrm{Cu}, \mathrm{Na}, \mathrm{Al}, \mathrm{K}, \mathrm{Sr}, \mathrm{Mg}, \mathrm{Fe}$ and $\mathrm{H}$. Lines of $\mathrm{Ca}^{+}, \mathrm{Sr}^{+}$ and $\mathrm{Mg}^{+}$ions were also observed. These are all species with relatively low lying excited states $<5 \mathrm{eV}$ (except for $\mathrm{H}$; its lines rapidly disappear), meaning the electron temperature can hardly exceed $1 \mathrm{eV}$. Molecular bands of $\mathrm{OH}$ $(\mathrm{A}-\mathrm{X})$ and $\mathrm{CaOH}(\mathrm{A}-\mathrm{X})$ and $(\mathrm{B}-\mathrm{X})$ electronic transitions have been identified.

The time-development of the emission spectra can be seen in figure 6 , for a series of shots with approximately $0.3 \mathrm{~g} / \mathrm{l}$ calcium chloride added to the water in the vessel.

The Cu I resonance lines $(324.8 \mathrm{~nm}, 327.4 \mathrm{~nm})$ are extremely optically thick throughout most of the lifetime, whereas the initially comparably thick $\mathrm{Ca}$ I resonance line $(422.7 \mathrm{~nm})$ decreases more rapidly in optical thickness. For both species clear self-reversal is visible, due to absorption in the cooler boundary layer. Ca II resonance lines (393.4 nm and $396.7 \mathrm{~nm}$ ) are optically thick initially but close to optically thin at $t \simeq 150 \mathrm{~ms}$, having a ratio of nearly 2 to 1 . The ion lines show no self-reversal indicating a lower ion density in the outer region.

Radiative transitions from higher excited states are mostly optically thin and rapidly decrease in intensity. In the autonomous phase, the bulk of the visible radia- 


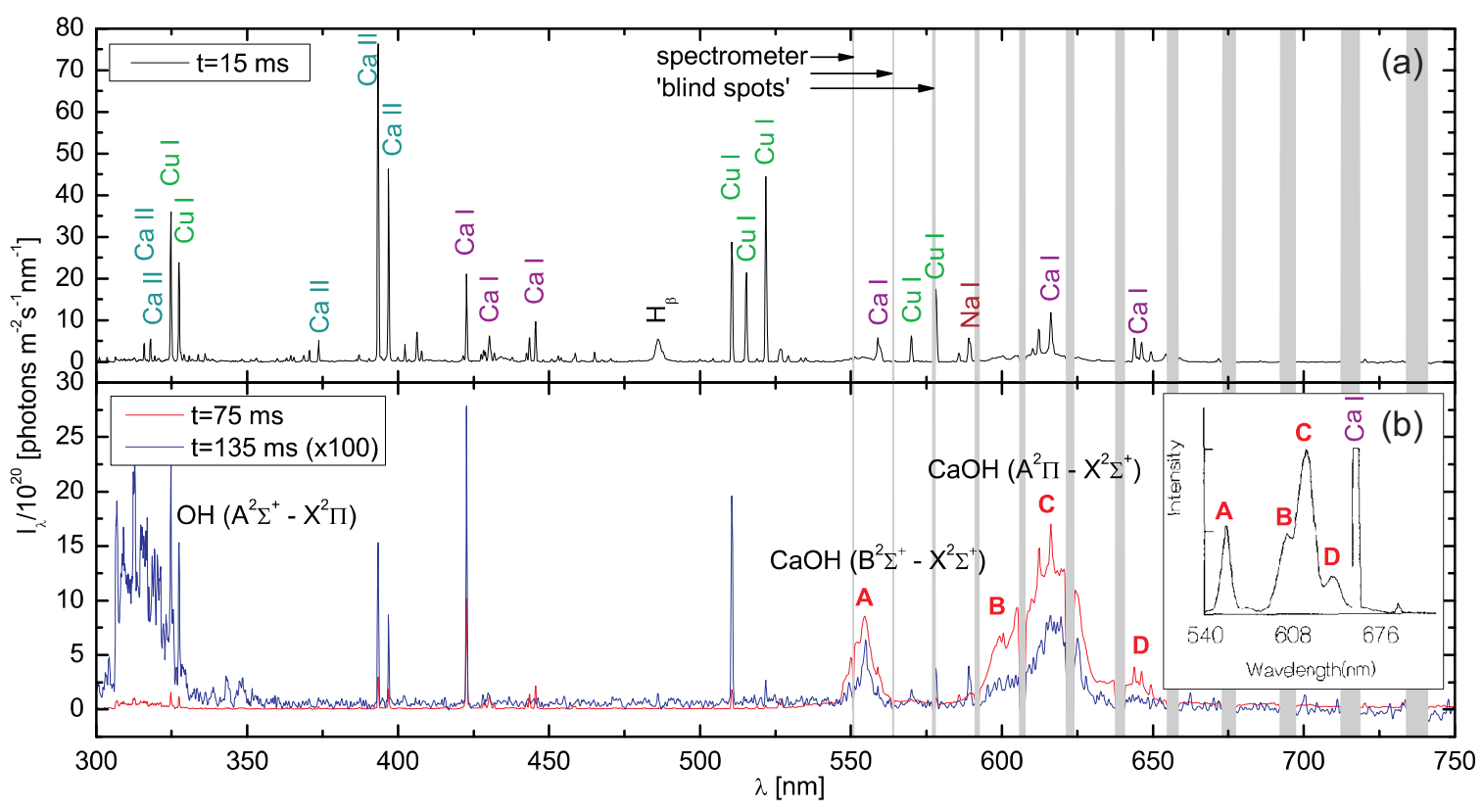

FIG. 6: (a) overview spectra recorded with échelle spectrometer (top view) at different times, with approximately $0.3 \mathrm{~g} / \mathrm{C} \mathrm{CaCl}_{2}$ added to the water. The resolution has been decreased artificially by convolution with a 40 pixel

FWHM Gaussian, to increase the visibility. The resulting resolving power is roughly 1000. The calibration is

absolute and the measurement at $t=135 \mathrm{~ms}$ has been scaled by a factor 100 . The small inset (b) shows a chemiluminescence spectrum copied from literature [6], assigned to the reaction of ${ }^{3} \mathrm{P}^{\circ} \mathrm{Ca}$ with $\mathrm{H}_{2} \mathrm{O}_{2}(\mathrm{see}$ paragraph III D 4). Peaks corresponding with those in the measured spectrum are indicated by the capital letters.

tion belongs to the green and orange/red $\mathrm{CaOH}$ molecular bands, determining the plasmoids characteristic color. Besides, the strong atomic and ionic resonance lines remain.

\section{Initial Phase - Atomic Line Broadening}

For $t<50 \mathrm{~ms}$ the high charge-carrier density causes a measurable broadening in some Stark sensitive lines. Relatively strong copper (contamination originating from the electrode) and lithium (added as salt to the water) lines enabled measurement up to $10 \mathrm{~cm}$ above the electrode $(t \approx 50 \mathrm{~ms})$, using the high resolution $(\lambda / \Delta \lambda \approx$ $100,000)$ spectrometer. At later times the (quadratic) Stark effect is overshadowed by competing Van der Waals broadening or spectrometer's apparatus width. For hydrogen $\mathrm{H}_{\beta}$, recorded using the échelle spectrometer, the intensity drops below the detection limit at $t \approx 70 \mathrm{~ms}$. Figure 7 (a) shows the broadening of the copper line at $406.264 \mathrm{~nm}$ at various heights above the central electrode.

The determination of $n_{\mathrm{e}}$ from the Lorentz component $w_{\mathrm{L}}(\mathrm{FWHM})$ of the fitted Voigt profile requires an estimate of the Van der Waals broadening contribution $w_{\mathrm{vdw}}$ due to neutral perturbers with density $n_{\mathrm{n}}$. This is obtained using a formula given by Griem [7], assuming $\mathrm{H}_{2} \mathrm{O}$ perturbers at atmospheric pressure and ideal gas density. The gas temperature is estimated based on the thermocouple data and Van der Waals broadening of Stark-insensitive lines. Using the calculated values for $w_{\mathrm{vdw}}, n_{\mathrm{e}}$ follows from the remaining Stark contribution to the Lorentz width (neglecting natural broadening) $w_{\mathrm{S}}=w_{\mathrm{L}}-w_{\mathrm{vdw}}$ :

$$
n_{\mathrm{e}}=n_{\mathrm{ref}} w_{\mathrm{s}} / w_{\text {ref }}
$$

For species other than hydrogen, reference widths $w_{\text {ref }}$ (including ion broadening contributions) from refs. [8, 9] (theoretical) and $[10,11]$ (experimental) were used. Errors in $n_{\mathrm{e}}$ are determined from calculating the minimum and maximum expected Van der Waals broadening contribution to the Lorentz width, based on a minimum and maximum estimate of the gas temperature, plus an additional error percentage in the Stark broadening parameters, as tabulated by Konjevic et al (e.g. $50 \%$ for $\mathrm{Cu} \mathrm{I}$ $406.246 \mathrm{~nm})$. For hydrogen lines, tables in ref. [12] were used to determine $n_{\mathrm{e}}$. Resulting electron densities for several spectral lines are shown in figure 7 (b).

\section{Atomic Line Ratios}

Intensity ratios of lines in the spectrum of the abundant atomic calcium were used to obtain information on plasma parameters. The electron density in the plasmoid varies over several orders of magnitude throughout its 


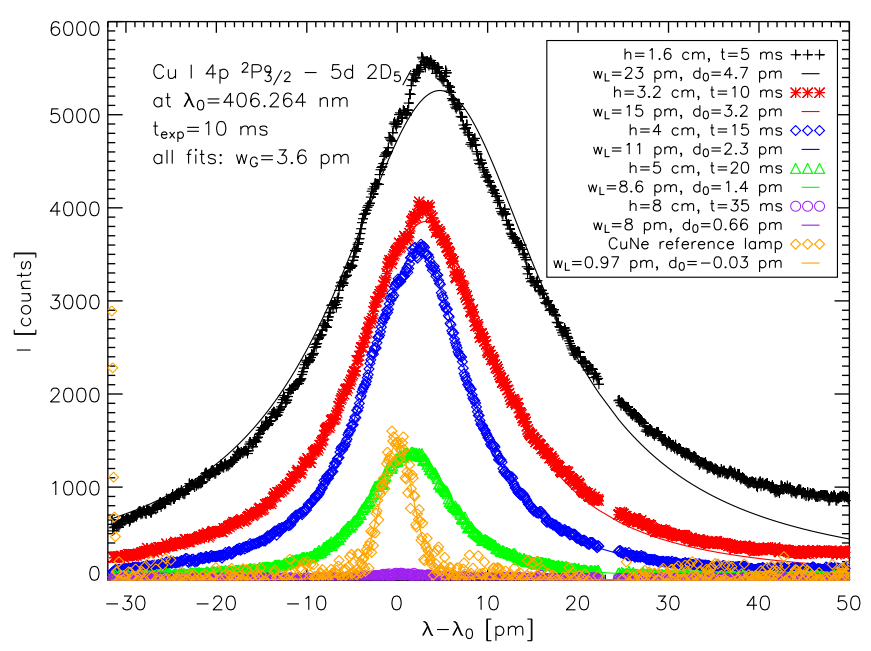

(a) Copper line at $406.3 \mathrm{~nm}$ at various heights above the electrode. The symbols are measured data; the solid lines are fits of a Voigt profile with a Gaussian width $w_{\mathrm{G}}=3.6 \mathrm{pm}$, Lorentz widths $w_{\mathrm{L}}$ and shift $d_{0}$ (see legend). The asymmetry may be caused by a narrow and unshifted contribution from the plasma edge, with lower $n_{e}$. Another possibility is an ion-broadening effect, that also leads to a higher wing in the direction of the shift.

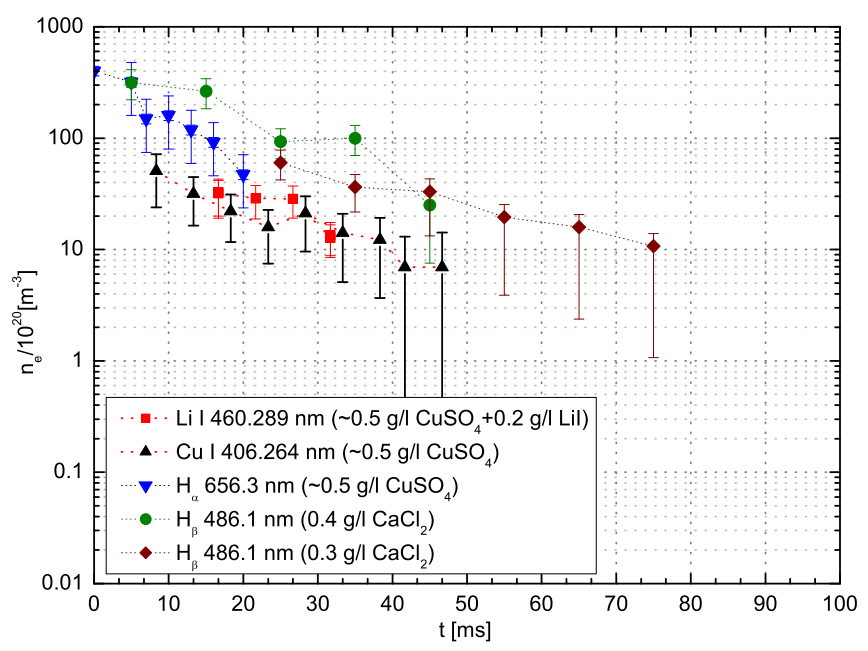

(b) Electron density derived from Stark width $w_{\mathrm{S}}$ of several spectral lines, using various salt additives. All measurements follow the same trend: an approximately exponentially decrease of $n_{\mathrm{e}}$ in time, up to the detection limit.

FIG. 7: Results of Stark broadening measurements, showing $n_{\mathrm{e}}>10^{20} \mathrm{~m}^{-3}$ in the first $75 \mathrm{~ms}$ of the discharge.

lifetime, making the interpretation of line ratios complex. Therefore, a collisional radiative model (CRM) was developed. The details of the CRM are beyond the scope of this article and only a single result is presented in figure 8 (the CRM is one of the topics of a Msc. thesis currently being written by AV). The optically thick transitions to the ground state are not used for comparing line ratios.

For $t \lesssim 0.45 \mathrm{~ms}$ the electron density is high enough to sustain an LTE between most lower lying excited states.
In this range the results of the CRM are identical to the Saha/LTE simulations at the NIST web page [13]. The electron temperature decreases from around $5000 \mathrm{~K}$ at the beginning to approximately $3000 \mathrm{~K}$ at $75 \mathrm{~ms}$. Later on the electron density is important and the measured line ratios indicate an exponentially decreasing $n_{\mathrm{e}}$. A quenching rate (non-radiative transitions to the ground state induced by heavy particle collisions) of $3 \cdot 10^{6} \mathrm{~s}^{-1}$ is used for all multiplets. This quenching rate is important for the line ratios and based on a rate coefficient for quenching of the $4 \mathrm{~s} 4 \mathrm{p}{ }^{3} \mathrm{P}^{\mathrm{o}}$ metastable state by $\mathrm{N}_{2}$, as reported in ref. [14], assuming atmospheric pressure and $T_{\mathrm{g}} \approx 2000 \mathrm{~K}$. The electron temperature remains in the range of $2000-3000 \mathrm{~K}$ at these later times.

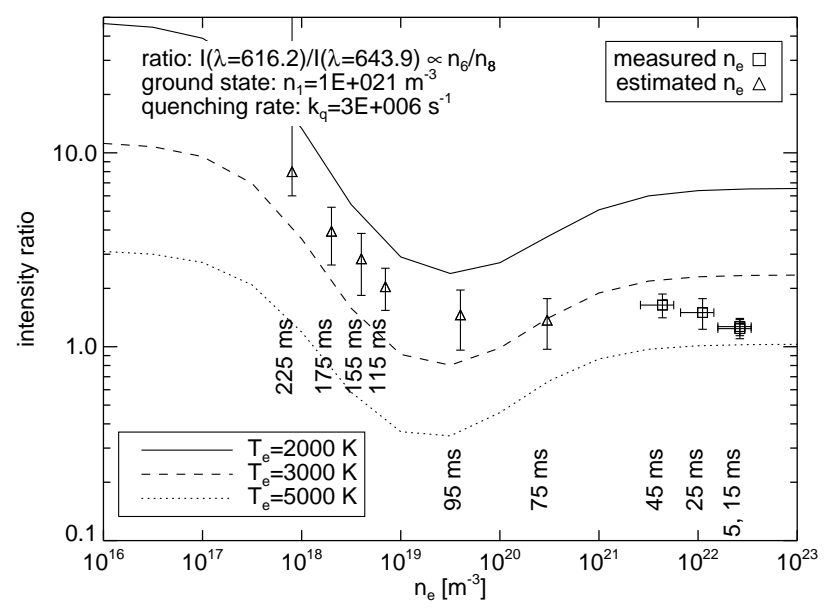

FIG. 8: Calculated line ratio from collisional radiative model for the Ca I $616.2 \mathrm{~nm} / 643.9 \mathrm{~nm}$ line pair. Also included in the graphs are measured line ratios, determined from spectra recorded using the échelle spectrometer (top view) at different times after triggering. For the first four points (squares) the density has been measured, using Stark broadening of the $\mathrm{H}_{\beta}$-line in the same spectra (the series indicated by

' $0.4 \mathrm{~g} / \mathrm{l} \mathrm{CaCl}_{2}$ ' in figure 7 (b)). For the other shots (triangles) the density could not be measured and the horizontal placement is estimated from the calculated and measured line ratios.

\section{Molecular Bands}

$\mathrm{OH}$ radicals may be formed from the (endothermal) decomposition reaction of water during the discharge, induced electrically (electrolysis) and/or by thermal dissociation:

$$
2 \mathrm{H}_{2} \mathrm{O} \rightleftarrows 2 \mathrm{H}_{2}+\mathrm{O}_{2} \rightleftarrows \mathrm{H}_{2}+2 \mathrm{OH} \text {. }
$$

The left part of figure 9 shows the $\mathrm{OH}\left(\mathrm{A}^{2} \Sigma^{+} \rightarrow \mathrm{X}^{2} \Pi\right)$ emission spectrum, recorded at different times. The evo- 
lution differs from that of most spectral lines: the intensity increases over a longer period (up to approximately $130 \mathrm{~ms}$, when the current is quenched), followed by a slower decay. The right part of figure 9 shows a comparison with a simulated $\mathrm{OH}$ emission spectrum, produced using the LIFbase simulation program [15]. The intensity of the vibrational band heads was matched with that of a measurement at $t=115 \mathrm{~ms}$. At atmospheric pressure a quenching rate of $5 \cdot 10^{-16} \mathrm{~m}^{3} \mathrm{~s}^{-1}$ was assumed for all levels, based on the quenching cross section for $\mathrm{H}_{2} \mathrm{O}$ perturbers at $2000 \mathrm{~K}$ from [16]. A rotational temperature of $15,000 \mathrm{~K}$ was assumed for all vibrational bands. The simulation indicates a non-thermal vibrational occupation distribution. The higher vibrational levels are overoccupied, likely because they are fed by chemical reactions. An investigation of the rotational occupation distribution of the $\mathrm{R}_{2}$-branch of the $\left(v^{\prime}, v\right)=(0,0)$ band between 306 and $310 \mathrm{~nm}$ shows that that the excited state rotational distribution is also non-thermal. A high rotational temperature $T_{\text {rot }}^{0,0}=O\left(10^{4} \mathrm{~K}\right)$ describes the higher rotational levels $(J>7)$ best, whereas $T_{\text {rot }}^{0,0}=O\left(10^{3} \mathrm{~K}\right)$ is more appropriate for $J<7$. The rotational distribution matches very well that of $\mathrm{OH}\left(\mathrm{A}^{2} \Sigma^{+}, v^{\prime}=0\right)$ produced by dissociative excitation of water vapor in literature [17, 18]. The value for the lower $J$ states is expected to be closest to the gas temperature.

The evolution of intensity of the $\mathrm{CaOH}$ molecular bands at $544-567 \mathrm{~nm}$ and $586-651 \mathrm{~nm}$ is similar to that of the $\mathrm{OH}$ bands: an initial increase throughout the period of the current flow, followed by a relatively slow decay. Therefore it is likely that $\mathrm{CaOH}$ is formed in the vapor phase in the $\sim 200 \mathrm{~ms}$ following the discharge triggering. Calcium is available in tap water in considerable quantities (in the order of $20 \mathrm{mg} / \mathrm{l}$ ). The CaOH emission persisted using various salt additives and also at a reduced calcium concentration achieved by de-ionizing. This suggests that the species reacting with $\mathrm{Ca}$ (or $\mathrm{Ca}^{+}$) to form $\mathrm{CaOH}$ is available in relatively large amounts, independent of the precise composition of the solution.

$\mathrm{CaOH}$ emission occurs in chemiluminescence reactions, for instance in flames. A reaction of calcium and water forming excited calcium hydroxide is possible, but the reaction cross section is relatively small. Ref. [6] reports intensity in a vapor (temperature of $800-900 \mathrm{~K}$ and pressure of $0.4 \pm 0.05$ Torr) consisting of a mixture of $70 \%$ by weight $\mathrm{H}_{2} \mathrm{O}_{2}$ and $30 \% \mathrm{H}_{2} \mathrm{O}$ is more than two orders of magnitude stronger than that using pure water vapor. Also, these authors were able to distinguish between reactions with ground state $\left({ }^{1} \mathrm{~S}\right)$ calcium atoms and those in the excited metastable $\left({ }^{3} \mathrm{P}^{\mathrm{o}}\right)$ state, leading to different reaction products: ${ }^{1} \mathrm{~S}$ produces mainly $\mathrm{CaO}$ (not detected here) whereas ${ }^{3} \mathrm{P}^{\mathrm{o}}$ results only in $\mathrm{CaOH}$ chemiluminescence. The emission spectrum of the latter reaction is shown in figure 6 (b) (inset). Based on the agreement of the observed spectra, the experimental reaction cross sections of ref. [6] and the abundance of $\mathrm{OH}$ radicals and excited (metastable) calcium atoms in the plasmoid, the following reactions are proposed as the source of $\mathrm{CaOH}$ emission:

$$
\begin{gathered}
\mathrm{Ca}\left({ }^{3} \mathrm{P}^{\mathrm{o}}\right)+\mathrm{H}_{2} \mathrm{O}_{2} \rightarrow \mathrm{CaOH}\left(\mathrm{A}^{2} \Pi \text { or } \mathrm{B}^{2} \Sigma^{+}\right)+\mathrm{OH} \\
\mathrm{Ca}+\mathrm{OH}(+\mathrm{M}) \rightarrow \mathrm{CaOH}\left(\mathrm{A}^{2} \Pi \text { or } \mathrm{B}^{2} \Sigma^{+}\right)(+\mathrm{M}) .
\end{gathered}
$$

For the latter reaction the chemical potential of the reactants in their ground state exceeds that of the products by an amount slightly greater than that for the first reaction, so that ground state $\mathrm{Ca}$ atoms will probably react as well. A possible source of $\mathrm{H}_{2} \mathrm{O}_{2}$ is the combination reaction of two $\mathrm{OH}$ radicals:

$$
\mathrm{OH}+\mathrm{OH}(+\mathrm{M}) \rightarrow \mathrm{H}_{2} \mathrm{O}_{2}(+\mathrm{M}) .
$$

The combination reactions $(5),(6)$ are most effective at low temperatures $\left(\lesssim 10^{3} \mathrm{~K}\right)$, e.g. on the outside of the plasma ball, causing the yellowish-green boundary layer (the orange/red band is suppressed by the response of the human-eye).

\section{E. Miscellaneous}

In the autonomous stage, after quenching the discharge current, the stored total charge was less than $10^{-10} \mathrm{C}$. No currents $>1 \mathrm{~mA}$ could be found and pick-up coils capable of measuring the earth magnetic field showed no signals. Therefore magnetic fields can be neglected.

\section{DISCUSSION}

The plasmoids appear to be more energetic as stated in refs. [2, 4]. Taking the radiated power and the ball size from figure 4 at $\mathrm{t}=180 \mathrm{~ms}$ and applying the StefanBoltzmann law one obtains a temperature of $920 \mathrm{~K}$, in agreement with the direct reading of the thermocouples (about $900 \mathrm{~K}$ ). This seems to be at variance to the small velocity (i.e. small buoyancy) in figure 4 (a). A possible explanation is the existence of water droplets within the ball which increases the average density.

Light emission and electrical signals (floating potential) can be found between up to $500 \mathrm{~ms}$ after shutdown of the generating current. This constitutes an analogy to ball lightning and rises the question which mechanism delivers the necessary energy (700 J radiation). Magnetic fields can be ruled out, and the electric field energy of is much too small. As was shown in section IIID 4, chemical processes most likely play an important role. The electric discharge energy is used to dissociate water, building up a reservoir of chemical energy. In the autonomous phase, this energy is released in the form of radiation via chemiluminescence reactions, e.g. with dissolved calcium.

Vibrationally excited molecules, such as $\mathrm{OH}$, may also play a role in electronic excitation of atoms in the autonomous phase. This may occur through direct excitation transfer from excited molecules to atoms. Another possibility are superelastic electron-molecule collisions, 

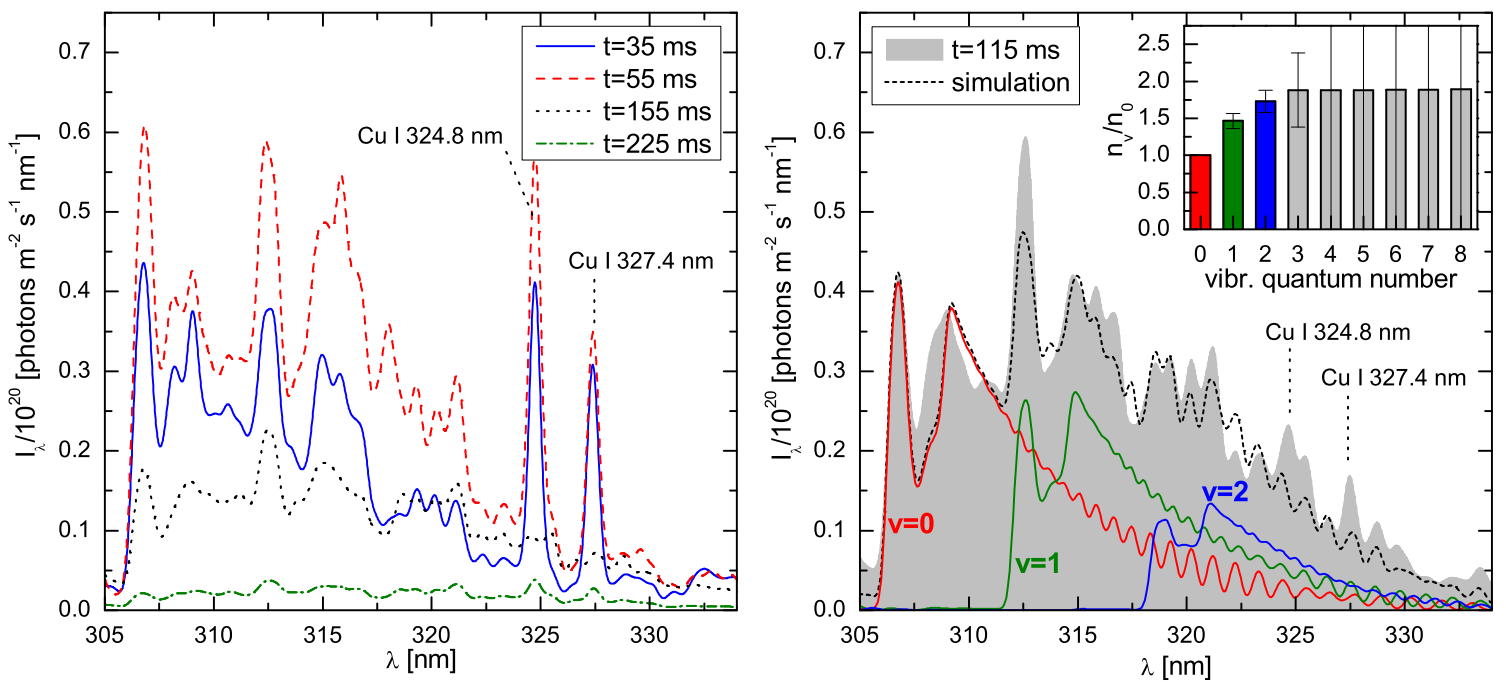

FIG. 9: Left: $\mathrm{OH}$ emission spectrum measured at different times. Maximum intensity is reached approximately at current zero. Right: comparison of measured and simulated spectrum. The contribution of the individual bands with vibrational quantum numbers $v=0,1$ and 2 are indicated by the solid (colored) lines. The inset shows the occupation of the vibrational levels relative to $v=0$ in the simulation.

followed by electron impact excitation. Both mechanisms may explain the remaining atomic line emission caused by electron impact excitation.

\section{CONCLUSIONS}

The observed plasmoids arise from a hot expanding plasma with relatively high electron density of $10^{22} \mathrm{~m}^{-3}$ to $10^{20} \mathrm{~m}^{-3}$ between $t=0$ and $t=75 \mathrm{~ms}$, determined from Stark broadening.

The electron temperature shows a fast initial drop from about $5000 \mathrm{~K}$ following slower decrease between $4000 \mathrm{~K}$ and $2000 \mathrm{~K}$ during the remaining part of the plasmoid's (visible) lifetime. Gas temperatures are much higher than previously thought. Values above $1200 \mathrm{~K}$ have been measured at $t \approx 200 \mathrm{~ms}$. Calcium hydroxide molecular band emission is the dominant visible radiation source in the autonomous stage. Comparison with chemiluminescence spectra and the observed high vibrational excita- tion of hydroxide radicals suggest that dissociation products of water store the (chemical) energy enabling the autonomously radiating behavior. The plasmoid's cooler boundary layer consists of electric double layers that may attribute to the characteristic shape of the balls.

\section{Acknowledgments}

We are grateful to H-J. Mans and S. Mettchen for their technical support. Prof. Dr. G.M.W. Kroesen and Dr. J.J.A.M. van der Mullen (Technische Universiteit Eindhoven) are thanked for their helpful comments and suggestions.

\section{References}

[1] A. G. Shabanov, Krivshich, B. Yu. Sokolovsky, and O. M. Zherebtsov. Proc. 9th Int. Symp. on Ball Lightning, Eindhoven, 2006.

[2] A. A. Egorov, S. I. Stephanov, and G. D. Shabanov. Phys. Usp., 47:99-101, 2004.

[3] Y. Sakawa, K. Sugiyama, T. Tanabe, and R. More. Plasma and Fusion Res.: Rap. Commun. 1, 1(39):1-2, 2006.

[4] A. A. Egorov and S. I. Stephanov. Tech. Phys., 47:1584$1586,2002$.
[5] B. Juettner, S. Noack, A. Versteegh, and G. Fussmann. Long-living Plasmoids from a Water Discharge at Atmospheric Pressure. In Proc. of the 28th ICPIG, Prague, Czech Republic, pages 2229-2234, July 2007.

[6] M. D. Oberlander, Kampf R.P., and J.M. Parson. Chemiluminescence reactions of $\mathrm{Ca}$ with hydrogen peroxide. Chem. Phys. Lett., 176(3,4):395-389, 1991.

[7] H. R. Griem. Plasma Spectroscopy. McGraw-Hill, New York, 1964.

[8] H. R. Griem. Spectral Line Broadening by Plasmas. Lon- 
don: Academic Press, 1974.

[9] M. S. Dimitrijević, S. Sahal-Bréchot, and V. Bommier. Astron. Astrophys. Suppl. Series, 89:581, 1991.

[10] N. Konjević and W. L. Wiese. Experimental Stark Widths and Shifts for Spectral lines of Neutral and Ionized Atoms. J. Phys. Chem. Ref. Data, 19(6):1307-1385, 1990.

[11] N. Konjević, A. Lesage, J. R. Fuhr, and W. L. Wiese. Experimental Stark Widths and Shifts for Spectral lines of Neutral and Ionized Atoms. J. Phys. Chem. Ref. Data, 31(3):819-927, 2002.

[12] M. A. Gigososy and V. Cardenosoz. New plasma diagnosis tables of hydrogen Stark broadening including ion dynamics. J. Phys. B: At. Mol. Opt. Phys., 29:4795-4838, 1996.

[13] Yu. Ralchenko, F.-C. Jou, D.E. Kelleher, A.E. Kramida, A. Musgrove, J. Reader, W.L. Wiese, and K. Olsen. Nist atomic spectra database (version 3.1.3). Available: http://physics.nist.gov/asd3, 2007.
[14] D Husain and J Schifino. J. Chem. Soc. Faraday Trans., 2(79):1265, 1983.

[15] J. Luque and D.R. Crosley. LIFBASE: Database and Spectral Simulation Program (Version 2.0.55). Report MP 99-009, SRI International, 1999.

[16] M. Tamura, P. A. Berg, J. E. Harrington, J. Luque, J. B. Jeffries, G. P. Smith, and D. R. Crosley. Collisional Quenching of $\mathrm{CH}(\mathrm{A}), \mathrm{OH}(\mathrm{A})$, and $\mathrm{NO}(\mathrm{A})$ in Low Pressure Hydrocarbon Flames. Combustion and Flame, 114:502-514, 1998.

[17] H. P. Broida and W. R. Kane. Rotational Intensity Distribution of $\mathrm{OH}$ and $\mathrm{OD}$ in an Electrodeless Discharge through Water Vapor. Phys. Rev., 89(5):10531059, 1953.

[18] G. R. Möhlmann, C. I. M. Beenakker, and F. J. de Heer. The rotational excitation and population distribution of $\mathrm{OH}\left(\mathrm{A}^{2} \Sigma^{+}, v^{\prime}=0\right)$ produced by electron impact on water. Chem. Phys., 13:375-385, 1975. 